\title{
Illuminating chromatin compaction in live cells and fixed tissues using SiR-DNA fluorescence lifetime
}

\author{
Colin Hockings ${ }^{1}{ }^{*}$, Chetan Poudel ${ }^{1 *}$, Kevin A. Feeney ${ }^{1}$, Clara L. Novo ${ }^{2}$, Mehdi S. Hamouda ${ }^{3,4,5}$, loanna Mela ${ }^{1}$, David \\ Fernandez-Antoran ${ }^{6}$, Pedro P. Vallejo-Ramirez ${ }^{1}$, Peter J. Rugg-Gunn ${ }^{2}$, Kevin Chalut ${ }^{3,4}$, Clemens F. Kaminski ${ }^{1}$, and Gabriele \\ Kaminski-Schierle ${ }^{1 凶}$ \\ ${ }^{1}$ Department of Chemical Engineering and Biotechnology, University of Cambridge, Cambridge CB3 OAS, United Kingdom \\ ${ }^{2}$ Epigenetics Programme, Babraham Institute, Cambridge CB22 3AT, United Kingdom \\ ${ }^{3}$ Wellcome Trust/Medical Research Council Stem Cell Institute, University of Cambridge, Cambridge CB2 1QR, United Kingdom \\ ${ }^{4}$ Cavendish Laboratory, Department of Physics, University of Cambridge, Cambridge CB3 OHE, United Kingdom \\ ${ }^{5}$ National Heart, Lung, and Blood Institute, National Institutes of Health, Bethesda 20892, MA, USA \\ ${ }^{6}$ Wellcome Sanger Institute, Hinxton, Cambridge CB10 1SA, United Kingdom \\ *These authors contributed equally.
}

\begin{abstract}
The global compaction state of chromatin in a nucleus is an important component of cell identity that has been difficult to measure. We have developed a quantitative method to measure the chromatin compaction state in both live and fixed cells, without the need for genetic modification, using the fluorescence lifetime of SiR-DNA dye. After optimising this method using live cancer cell lines treated to induce chromatin compaction or decompaction, we observed chromatin compaction in differentiating epithelial cells in fixed tissue sections, as well as local decompaction foci that may represent transcription factories. In addition, we shed new light on chromatin decompaction during embryonic stem cell transition out of their naïve pluripotent state. This method will be useful to studies of nuclear architecture, and may be easy, cheap, and accessible enough to serve as a general assay of 'stem-ness'.

chromatin compaction | SiR-DNA | Fluorescence Lifetime Imaging Microscopy | embryonic stem cells | live-cell imaging

Correspondence: gsk20@cam.ac.uk
\end{abstract}

Introduction. Chromatin architecture plays a crucial role during differentiation and in the maintenance of cell identity. However, a quick and accessible method to determine the level of chromatin compaction or decompaction is lacking. Currently, most studies of nuclear architecture rely on genomic sequencing-based methods to measure chromatin compaction, such as High Throughput Chromosome Conformation Capture (Hi-C) (1-4), Chromatin Immunoprecipitation Sequencing (ChIP-seq) $(5,6)$ or Assay for Transposase-Accessible Chromatin using sequencing (ATAC-seq) (7). These methods produce outstanding detail on local chromatin structure, domain structure and long-range interactions, but generally represent an expensive snapshot of a populations of cells. There is a need for robust, reproducible methods to study single cells with reasonable throughput, as well as to test hypotheses generated by sequencing. Moreover, if these alternative methods were sufficiently accessible, they may be useful in stem cell and developmental biology as a biomarker of 'stem-ness', as nuclei tend to compact with differentiation (8-17). However, current methods require fixing cells, stable expression of fluorescent proteins, inaccessible instruments, analysis of subtle changes in heterochromatin morphology, are very low throughput, or are only applicable to certain cell types (see Table 1) (1-8, 15, 18-38), hence current methods have not been widely adopted. In this study, we show that the fluorescence lifetime of SiR-DNA (a far-red nuclear staining dye previously named SiR-Hoechst) (39) can be used as a robust measure of chromatin compaction in live cells, and can be applied to any sample as simply as staining with common live-cell DNA stains.

The fluorescence lifetime is the average time a fluorophore spends in the excited state after excitation, and this can be highly sensitive to the fluorophore's molecular microenvironment (40). Many successful fluorescent biosensors are based on fluorescence lifetime measurements (41-43), as the fluorescence lifetime is generally independent of fluorophore concentration, illumination conditions or microscope setup. The fluorescence lifetime of fluorophores can be mapped spatially using fluorescence lifetime imaging microscopy (FLIM) $(44,45)$, a technique accessible in many academic microscopy facilities. Throughout this study, the fluorescence lifetime of SiR-DNA was measured using time-correlated single photon counting (TCSPC) FLIM, which provides single-photon sensitivity and the highest signal-to-noise ratio among all the FLIM implementations (46).

We applied FLIM of SiR-DNA dye to easily measure the chromatin compaction in live cells using cell lines treated with artificial compaction or decompaction stimuli, and Embryonic Stem (ES) cells lacking the pluripotency factor NANOG. In addition, we showed that naïve stem cells undergo chromatin decompaction together with Rex1 downregulation as they transition out of the naïve pluripotent stem cell state. Moreover, this technique also works in standard fixed tissue, as we could observe the changes in chromatin compaction in oesophagus epithelium in situ as basal cells differentiate. Therefore, measuring the fluorescence lifetime of SiR-DNA represents an ideally suited method to understand the chromatin compaction state 


\begin{tabular}{|c|c|c|c|c|c|c|c|c|}
\hline Techniques & References & $\begin{array}{l}\text { Gene } \\
\text { locus }\end{array}$ & $\begin{array}{l}\text { Single } \\
\text { cell }\end{array}$ & $\begin{array}{l}\text { Live } \\
\text { cell }\end{array}$ & $\begin{array}{l}\text { Instrument } \\
\text { availability }\end{array}$ & $\begin{array}{c}\text { Through- } \\
\text { put }\end{array}$ & $\begin{array}{l}\text { Robust } \\
\text { analysis }\end{array}$ & $\begin{array}{l}\text { Cell appli- } \\
\text { cability }\end{array}$ \\
\hline SiR-DNA FLIM & This study & No* & Yes & Yes & $\mathrm{B}$ & B\# & $\bar{B}$ & $\mathrm{~A}$ \\
\hline DAPI/Hoechst FLIM & $(36,37)$ & $\mathrm{No}^{*}$ & Yes & No & $\mathrm{C}$ & B\# & B & $\overline{\mathrm{A}}$ \\
\hline $\begin{array}{ll}\text { Histone tagged } & \text { FLIM- } \\
\text { FRET sensor } & \end{array}$ & $\begin{array}{c}(18- \\
20,38)\end{array}$ & $\mathrm{No}^{*}$ & Yes & Yes & B & B\# & B & $\mathrm{C}$ \\
\hline FRAP & $(8,21)$ & No* & Yes & Yes & B & $\mathrm{C}$ & $\mathrm{C}$ & B \\
\hline $\begin{array}{l}\text { Histone modification im- } \\
\text { munofluorescence, FISH }\end{array}$ & $(22-24)$ & Yes & Yes & No & A & A & $\mathrm{E}$ & A \\
\hline $\begin{array}{l}\text { Morphology of DAPI or } \\
\text { Hoechst staining }\end{array}$ & $(8,24)$ & $\mathrm{No}^{*}$ & Yes & Yes & A & A & $\mathrm{E}$ & $\mathrm{E}$ \\
\hline ESI & $(25,26)$ & No & Yes & No & $\mathrm{D}$ & $\mathrm{E}$ & $\bar{A}$ & $\overline{\mathrm{A}}$ \\
\hline ChromEMT & (27) & No & Yes & No & $\mathrm{C}$ & $\mathrm{E}$ & $\mathrm{E}$ & A \\
\hline $\begin{array}{l}\text { Chromosome Conforma- } \\
\text { tion Capture }(3 \mathrm{C}, 5 \mathrm{C}, \mathrm{Hi}- \\
\text { C) }\end{array}$ & $(1-4)$ & Yes & No \$ & No & Seq. & Seq. & Seq. & $\bar{A}$ \\
\hline $\begin{array}{l}\text { ChIP, DamID, ATAC-seq, } \\
\text { Bisulphite Sequencing }\end{array}$ & $\begin{array}{c}(5-7,15 \\
28,29)\end{array}$ & Yes & No & No & Seq. & Seq. & Seq. & A \\
\hline AFM & $(30-32)$ & No & Yes & Yes & B & $\mathrm{E}$ & B & $\mathrm{D}$ \\
\hline $\begin{array}{l}\text { Micropipette } \quad \text { squeezing, } \\
\text { microfluidic } \quad \text { squeezing, } \\
\text { substrate stretching }\end{array}$ & $(33-35)$ & No & Yes & Yes & $\mathrm{E}$ & $\mathrm{D}$ & $\mathrm{D}$ & $\mathrm{D}$ \\
\hline
\end{tabular}

\begin{tabular}{llll}
\hline Instrument availability & Throughput & Robust analysis & Cell applicability \\
\hline A: in most departments, & A: $1-10$ cells per 10 sec- & A: direct read-out, B: curve fit- & A: Any cell or tissue, B: \\
B: in most universities, & onds (confocal z-stack), & ting, C: complex curve fitting, cell line transiently expressing \\
C: in most countries, D: & B: 1-20 cells per 100 sec- & D: automated morphology anal- & transgene, C: clonal cell line \\
a few in the world, E: & onds (FLIM), C: 1 cell & ysis, E: subjective morphology & stably expressing transgene, D: \\
custom-built, Seq.: in & per minute, D: 1 cell per & analysis, Seq.: thorough bioin- & only isolated nuclei or cells \\
most universities & 10 minutes, E: 1 cell per & formatics & with thin cytosol, E: only cells \\
& hour, Seq.: One experi- & & with a certain nuclear architec- \\
& ment per week & & ture. \\
\hline
\end{tabular}

Table 1. A comparison of various methodologies available to assess chromatin compaction. FRET: Förster Resonance Energy Transfer, FRAP: Fluorescence Recovery after Photobleaching, FISH: Fluorescence In Situ Hybridization, ESI: Electron Spectroscopic Imaging, ChIP: Chromatin immunoprecipitation, AFM: Atomic Force Microscopy, Seq: Next Generation Sequencing. *Could provide single gene locus information in combination with dCas9-FP or TALEN-FP, \# Throughput is faster with new FLIM systems, \$ Single cell $\mathrm{Hi}-\mathrm{C}$ is possible, but is technically very challenging and expensive. A legend for A,B,C,D,E rankings is included at the bottom with a subjective assessment of instrument availability, throughput, analysis robustness and cell applicability.

of live or fixed cells with direct relevance to the study of nuclear architecture, stem cells, and cell differentiation.

Results. To first validate the SiR-DNA FLIM sensor, human fibroblasts and neuroblastoma cells were subjected to treatments that induce chromatin compaction or decompaction (Fig 1). We used ATP starvation (with sodium azide, $\mathrm{NaN}_{3}$, and 2-deoxyglucose, 2-DG) to cause chromatin compaction, and histone deacetylase (HDAC) inhibition (with Trichostatin A) to induce chromatin decompaction $(18,19,36)$. Cells were subjected to the different treatments and stained with $1 \mu \mathrm{M}$ SiR-DNA and 10 $\mu \mathrm{M}$ verapamil (a pump inhibitor that improves live cell staining (39)) for one hour, before changing to fresh media lacking SiR-DNA and imaging by FLIM (Fig S1). ATP starvation reduced SiR-DNA fluorescence lifetime and HDAC inhibition increased SiR-DNA fluorescence lifetime significantly, demonstrating that this sensor can measure changes in chromatin compaction status (Fig 1a, b).
SiR-DNA FLIM revealed similar fluorescence lifetime changes in SH-SY5Y neuroblastoma cells subjected to ATP starvation and HDAC inhibition, indicating that these effects are cell type independent (Fig 1c). Moreover, these changes were reversible, as the fluorescence lifetime recovered to untreated cell levels one hour after washing off the various treatments (Fig 1c). The measured compaction (ATP starvation) and decompaction (HDAC inhibition) of chromatin was also confirmed by stiffening and softening of the nucleus, respectively (Fig 1d,e). This was measured using atomic force microscopy (AFM), which has been previously demonstrated to measure nuclear compaction in sufficiently thin cells such as fibroblasts (30-32), but provides very low throughput compared to the SiR-DNA based method. In addition to these relatively mild changes in chromatin compaction, SiR-DNA lifetime showed decreased lifetime in cells dying from cell cycle arrest (epothilone B) and cells undergoing osmotic shock with dextrose, a non-physiological treatment that compacts nuclei by 
bioRxiv preprint doi: https://doi.org/10.1101/2020.05.02.073536; this version posted May 2, 2020. The copyright holder for this preprint (which was not certified by peer review) is the author/funder, who has granted bioRxiv a license to display the preprint in perpetuity. It is made available under aCC-BY-ND 4.0 International license.

a

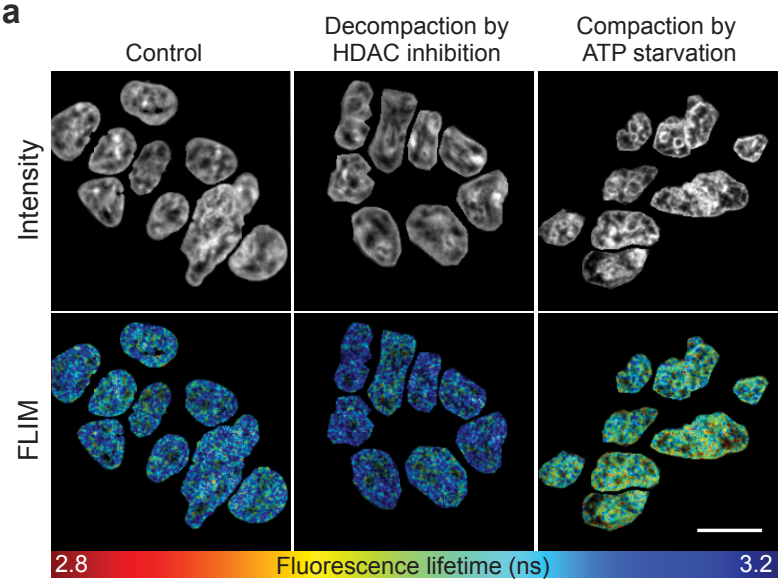

d

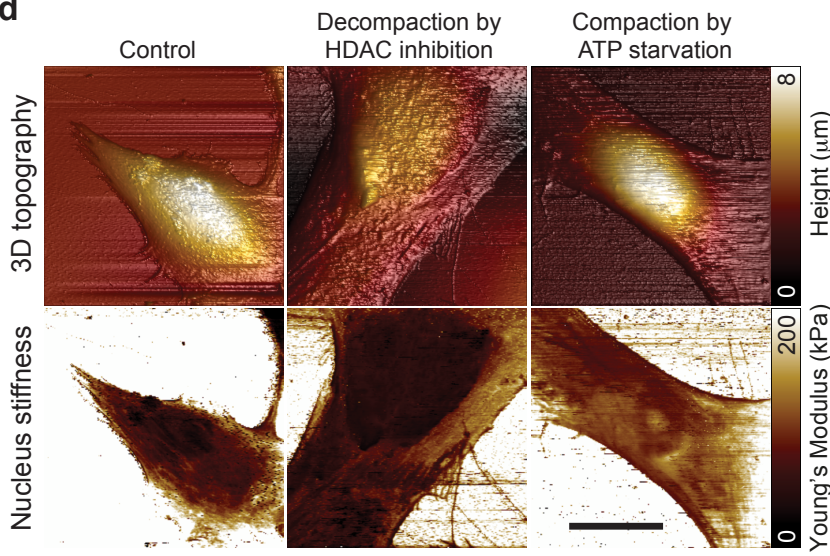

f

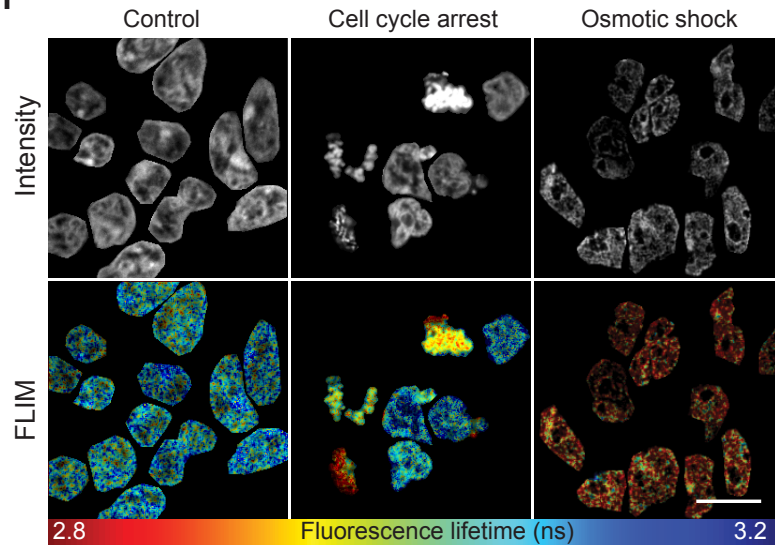

b

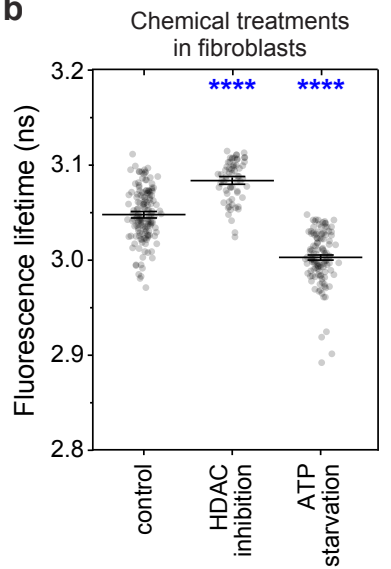

C

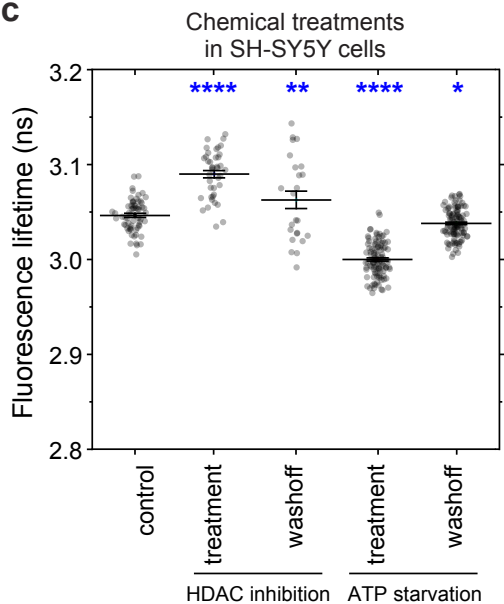

e

AFM: Quantitative Biomechanics
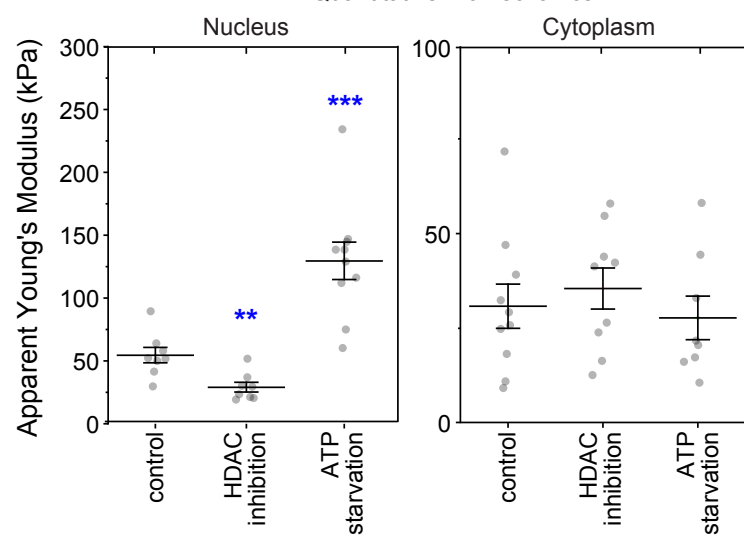

g

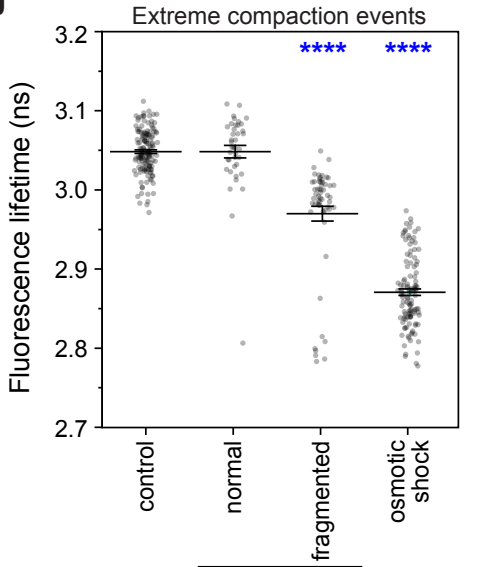

$\overline{\text { cell cycle arrest }}$

Fig. 1. Fluorescence lifetime of SiR-DNA is a novel measure of nuclear compaction in live cells. (a) Representative fluorescence intensity and lifetime images and (b) plot of SiR-DNA fluorescence lifetimes show that treatments causing nuclear compaction such as NaN3+2-DG (ATP starvation) decrease SiR-DNA fluorescence lifetime, whereas treatments causing nuclear decompaction such as Trichostatin A (HDAC inhibition) increase SiR-DNA fluorescence lifetime. Fibroblasts were treated for 1 hour before imaging. 4 independent experiments were performed with >10 images per sample. (c) Similar fluorescence lifetime changes were seen in SH-SY5Y cells undergoing the same treatments. SiR-DNA fluorescence lifetime recovers towards control levels when cells were allowed to recover for 1 hour in untreated media (washoff) before imaging. 3 independent experiments were performed with >10 images per sample. (d) Representative AFM height maps and Young's Modulus maps and (e) apparent Young's modulus of nucleus and cytoplasm reveal that compaction or decompaction treatments render nuclei stiffer or softer, respectively, but have no effect on cytoplasm stiffness. Fibroblasts treated as in Fig 1a-b. Each point represents one cell, $>3$ independent experiments with $>3$ cells per sample analysed. (f) Representative fluorescence intensity and lifetime images of fibroblasts and $(\mathrm{g})$ plot of SiR-DNA fluorescence lifetimes show that treatments causing extreme nuclear compaction decrease SiR-DNA fluorescence lifetime. Epothilone B (cell cycle arrest) caused some nuclei to adopt a fragmented morphology and only those dying cells had a lower SiR-DNA fluorescence lifetime, and $20 \%$ dextrose (osmotic shock) caused a dramatic reduction in SiR-DNA fluorescence lifetime. 4 independent experiments with $>10$ images per sample analysed. Mean +/- SEM is shown for each plot, where individual points represent one nucleus. Data in b, c, and g were analyzed using unpaired one-way ANOVA, Sidak's multiple comparisons test where all treatments were compared to control. Data in e were analysed using unpaired, two-tailed t-test with Welch's correction instead of ANOVA as there are large differences in variances between different treatments. The asterisks in the plots represent significant differences from control: ${ }^{*} p<0.05,{ }^{* *} p<0.01$, ${ }^{* * *} p<0.0001$. All scale bars are $20 \mu \mathrm{m}$. 
removing water (Fig 1e, f). Notably, the changes in SiR-DNA fluorescence lifetime cannot be attributed to changes in SiR-DNA staining or intensity (Fig S2).

Cutting edge genomics methods such as $\mathrm{Hi}-\mathrm{C}$ have mapped chromatin interactions during ES cell differentiation in high resolution, however how different ES cell culture conditions affect chromatin compaction and pluripotency remains unclear (reviewed in (47)). Most imaging assays of chromatin compaction have failed to perform well in live cells or required genetic modifications, precluding their adoption in the stem cell field. Stem cell researchers have previously resorted to imaging the chromocentre morphology in fixed cells $(8,24)$ or less accessible methods such as microfluidic cell squeezing (32) or Electron Spectroscopic Imaging (ESI) $(25,26)$ (see Table 1). We therefore investigated whether SiR-DNA fluorescence lifetime could provide a quick, affordable, and sensitive method to detect changes in chromatin architecture in live mouse ES cells.

ES cells are characterised by a strikingly open chromatin configuration, including inside constitutive heterochromatin domains $(8,9,48,49)$. The transition from the pluripotent to the committed state features extensive genome reorganisation associated with chromatin compaction and the formation of condensed heterochromatin domains, which is thought to form a repressive environment to facilitate lineage commitment (8-15). Furthermore, differentiating ES cells show a significant increase in cellular (50) and nuclear stiffness (51). Compared to ES cells in serum-LIF medium, ES cells reprogrammed to a naïve state using 2i-LIF medium (serum-free N2B27 medium containing inhibitors of the MEK and GSK $3 \beta$ pathways) $(52,53)$ are characterised by higher cellular homogeneity and low levels of DNA methylation, which has been strongly associated with a more permissive chromatin state (29, 47, 54-56). Surprisingly, despite the lower DNA methylation, the SiR-DNA fluorescence lifetime was reduced in 2i-LIF cultured ES cells, indicating that the chromatin in these naïve cells was significantly more compact compared to ES cells maintained in serum-containing medium (Fig 2a, b). To verify our observation that the chromatin was compacted in these ES cells using an established assay, we also examined the chromocenter morphology $(8,24)$. Naïve pluripotent ES cells in 2i-LIF medium showed an increase in chromocenter numbers (Fig S3), confirming a general compaction of the genome during reversion to the naïve pluripotent state. Our data support that naïve ES cells transition through a less-compact 'formative period' (57) state before differentiating and compacting. Indeed, we found that in a time-course experiment, as naïve Rex1-GFP-expressing cells left the naïve state and downregulated Rex1-GFP (58), they had an increased SiR-DNA fluorescence lifetime indicating chromatin decompaction (Fig 2c, S4).

Once through the formative transition state, ES cells start to differentiate and the chromatin starts to compact (8-15). The pluripotent transcription factor NANOG is required to maintain a globally open chromatin in ES cells as Nanog-/- nuclei were shown to be more compact using ESI and scoring changes to chromocenter morphology $(8,24)$. In this study, we have confirmed this finding as Nanog-/- ES cell nuclei displayed a shorter SiR-DNA fluorescence lifetime compared to wild-type cells (Fig 2d,e). With these data we can draw a simplistic model encompassing the spectrum of chromatin compaction and measurable by FLIM of SiR-DNA (Fig 2f), where naïve ES cells (represented in this study by ES cells in 2i-LIF) first decompact (represented by ES cells in serum-LIF or 17-25 hours after $2 \mathrm{i}$ withdrawal), and then start to compact (represented by Nanog-/- ES cells), and subsequently differentiate into the various mature cell types with very compact chromatin (represented by fibroblasts and SH-SY5Y cells).

While the ability to measure chromatin compaction in live cells may be optimal for cells in culture, we also found that SiR-DNA fluorescence lifetime can be applied to fixed tissues allowing the study of chromatin architecture in situ with no genetic modification required. Mouse oesophagus cryosections were stained with SiR-DNA as well as wheat-germ agglutinin (WGA) to label epithelial cell membranes and imaged with FLIM (Fig 3a,b). The basal cells (stem cells) had a higher fluorescence lifetime than the suprabasal (differentiating) cells, which is expected since extensive genome reorganisation associated with chromatin compaction occurs upon differentiation (59). Interestingly, there was a large variation in the fluorescence lifetimes of the suprabasal cells, including many nuclei containing a high-lifetime spot. This suggests that there may be a general compaction of the chromatin during differentiation, coupled with a partial decompaction of some regions of the nucleus involved in the transcription of keratin and other keratinocyte genes (59). These data demonstrate that measuring SiR-DNA fluorescence lifetime is an effective new tool that can contribute to studies of nuclear architecture and stem cell differentiation in situ, in ex-vivo tissue sections.

Discussion. In this study, we have shown that SiR-DNA FLIM is an accurate and quantitative measure of chromatin compaction. FLIM of SiR-DNA provides excellent sensitivity and allows for imaging any cell in their native state without requiring fluorescent protein expression. While FLIM is not a very common microscopy technique, there are FLIM systems available in the microscopy suites of many academic institutes, and recent developments in FLIM technology are making FLIM easier, faster and more accessible than ever.

First, we validated the assay in fibroblasts and SH-SY5Y cells using standard chemical treatments to compact and decompact chromatin. We then illuminated new details of chromatin decompaction during naïve ES cell differentiation, as well as confirming recently published results on the nuclear architecture of ES cell knockouts of Nanog. Finally, we showed that this method is amenable to studies of chromatin compaction in fixed tissue slices, demonstrating that this method really is applicable across 


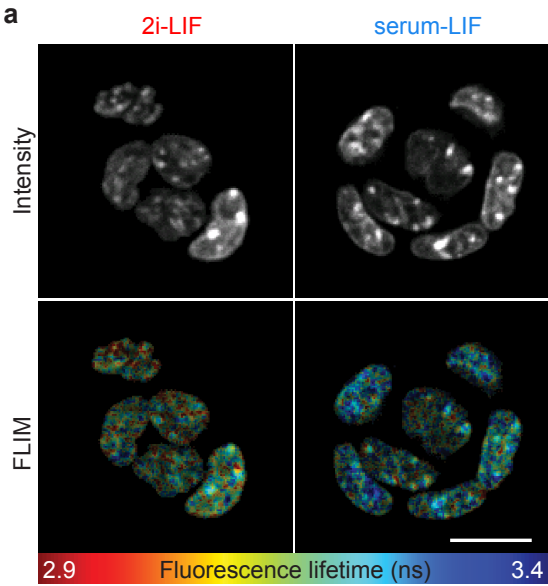

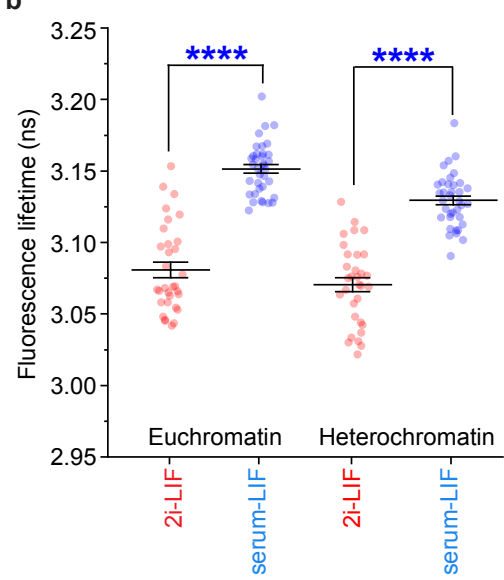

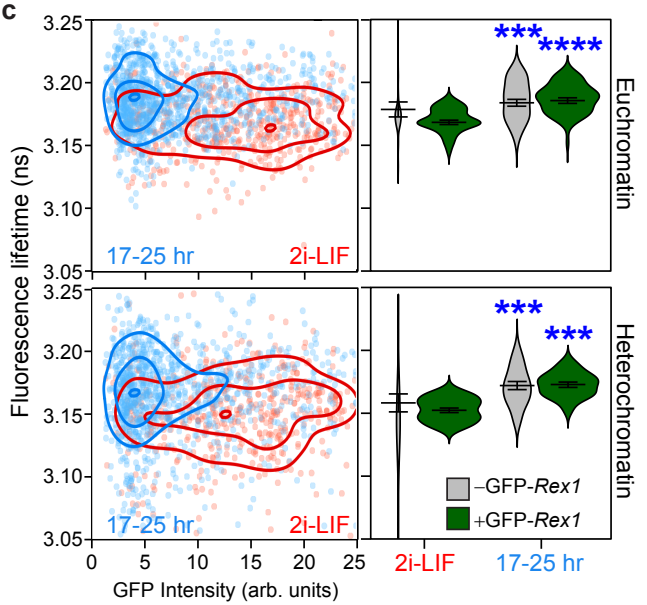

$\mathbf{f}$

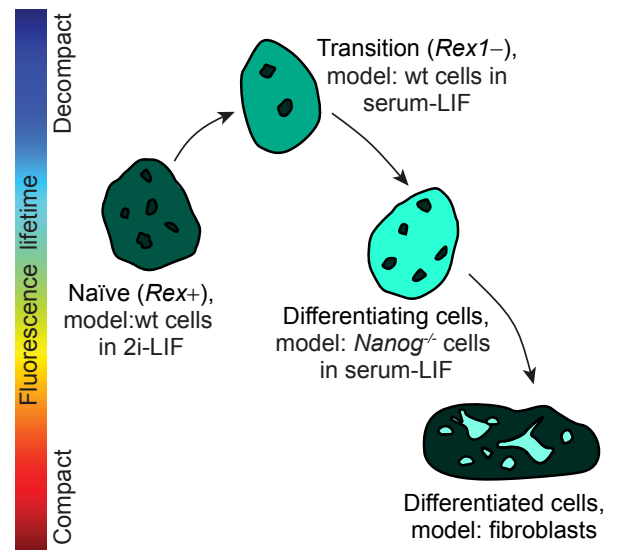

d

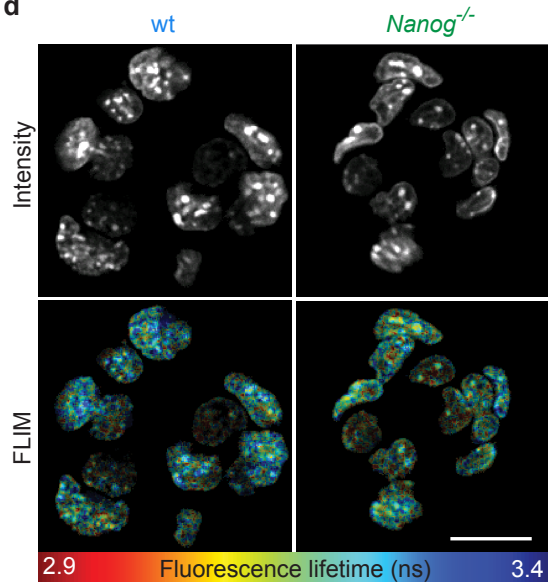

e

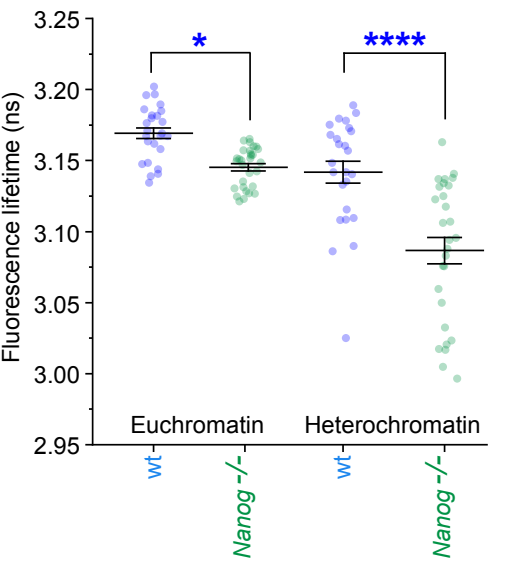

Fig. 2. SiR-DNA fluorescence lifetime analysis reveals that murine naïve embryonic stem cells transit through a genome decompaction stage before committing to differentiation. (a) Fluorescence intensity and lifetime images and (b) plot of SiR-DNA fluorescence lifetimes show that naïve ES cell nuclei (2i-LIF medium) display a lower fluorescence lifetime (more compact) than transition ES cell nuclei (serum-LIF medium), in both euchromatin and heterochromatin regions. Each point represents one image, 3 independent experiments with $>8$ images per sample. Unpaired one-way ANOVA with Sidak's multiple comparisons test. (c) Rex1-GFP ES cell time course after $2 \mathrm{i}$ withdrawal shows that nuclei increase their SiR-DNA fluorescence lifetime (become less compact) as they lose Rex1-GFP expression (exit naïve state). Each point represents one cell, 3 independent experiments with $>9$ images per sample. Threshold for 'GFP-positive' is 5 intensity units. All timepoints are compared against the GFP positive 2i-LIF condition using unpaired one-way ANOVA with Dunnett's multiple comparisons test. (d) Fluorescence intensity and lifetime images and (e) plot of SiR-DNA fluorescence lifetimes show that Nanog-/-cell nuclei display a lower fluorescence lifetime (more compact) than wildtype ES cell nuclei (both in serum-LIF), in both euchromatin and heterochromatin regions. Each point represents one image, 3 independent experiments with $>8$ images per sample analysed. Unpaired one-way ANOVA with Sidak's multiple comparisons test. (f) Model of ES cell differentiation, showing that naïve ES cells (Rex1 positive cells in 2i-LIF) first go through a chromatin decompaction stage (Rex1 negative cells in serum-LIF), before further differentiation and chromatin compaction (Nanog-/- cells, fibroblasts, and SH-SY5Y cells). Mean +/- SEM is shown for each plot. ${ }^{*} p<0.05,{ }^{* *} p<0.01,{ }^{* * *} p<0.001,{ }^{* * * *} p<0.0001$. Scale bars are $30 \mu \mathrm{m}$.

biological contexts with no genetic modification required. We have shown that the measurement of SiR-DNA fluorescence lifetime is compatible with expression of other fluorescent markers, such as Rex1-GFP to mark naïve ES cells or WGA staining to mark epithelial cells. We expect that this method could also be used in combination with fluorescent dCas9 or fluorescence in situ hybridisation (FISH) to examine the local chromatin state of particular loci.

Our data highlight the need for independent methods to measure chromatin compaction, as our observations challenge previous assumptions that lower levels of DNA methylation in 2i-treated ES cells (29) also results in less compaction. There have been some reports suggesting that the epigenetic marker $\mathrm{H} 3 \mathrm{~K} 27 \mathrm{me} 3$ may be able to repress parts of the genome and counterbalance lower levels of
DNA methylation, at least within some loci of $2 \mathrm{i}$-treated cells $(60,61)$.

Our results showing that naïve ES cells decompact upon $2 \mathrm{i}$ withdrawal support previous data that Rex1 downregulation occurs at the same time as a transition to an auxetic nucleus phenotype (32). Therefore, this decompacted chromatin state may be part of the same formative period (57) whereby naïve ES cells must first decompact to reach a transition state where chromatin is accessible to a gene regulatory switch to gain competence for lineage commitment $(14,21,32,62)$.

Chromatin compaction has been shown to correlate with differentiation state, as differentiated cells generally compact the regions of their genome not required for their mature function to maintain their identity (8-17). In this study we have shown some notable exceptions to this rule, as naïve ES cells initially decompacted upon leaving the 
bioRxiv preprint doi: https://doi.org/10.1101/2020.05.02.073536; this version posted May 2, 2020. The copyright holder for this preprint (which was not certified by peer review) is the author/funder, who has granted bioRxiv a license to display the preprint in perpetuity. It is made available under aCC-BY-ND 4.0 International license.

a
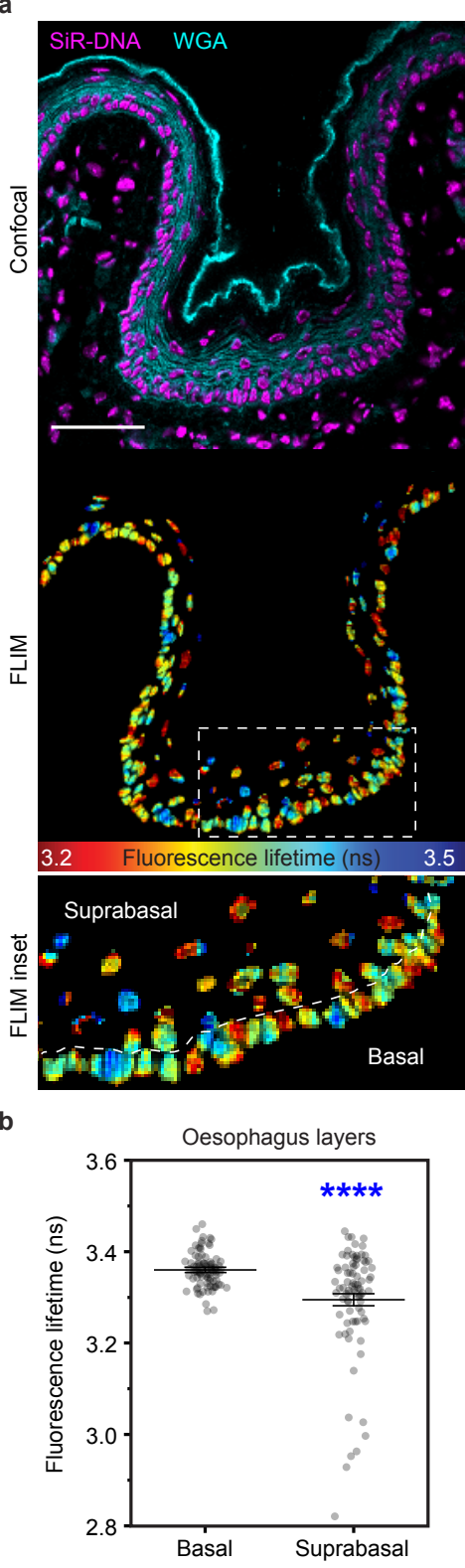

Fig. 3. Chromatin compaction in fixed tissues. (a) Fluorescence intensity and lifetime image and (b) plot of SiR-DNA fluorescence lifetimes in fixed mouse oesophagus tissue show a longer lifetime (less compact) in basal stem cells than differentiating suprabasal cells. Wheat Germ Agglutinin (WGA) labels epithelial cell membranes. Each point represents one nucleus, data from one representative image shown, out of 6 mice analysed. Unpaired t-test with Welch's correction. Mean $+/-$ SEM is shown, ${ }^{\star * * *} p<0.0001$. Scale bar: $50 \mu \mathrm{m}$.

naïve state, and differentiating keratinocytes appear to have foci of decompaction, but as long as these types of exceptions are kept in mind, this method may be viable as a general 'stem-ness' assay. Moreover, we foresee that this method could be amenable to a plate-reader format for high content screens of stem cell phenotypes.

\section{ACKNOWLEDGEMENTS}

This project has received funding from the European Union's Horizon 2020 research and innovation programme under Grant Agreement No. 722380 (SUPUVIR). G.S.K.S. and C.F.K. acknowledge funding from the Wellcome Trust, the UK Medical Research Council (MRC), Alzheimer Research UK (ARUK), and

Infinitus China Ltd. C.F.K. acknowledges funding from the UK Engineering and Physical Sciences Research Council (EPSRC). P.J.R.-G. acknowledges funding from the UK Biotechnology and Biological Sciences Research Council (BBSRC) (BB/M022285/1 and BBS/E/B/000C0422) and the European Commission Network of Excellence EpiGeneSys (HEALTH-F4-2010-257082). D.F-A. was supported by a core grant from the Wellcome Trust to the Wellcome Sanger Institute. We thank Ricardo Henriques lab for this LaTeX template.

\section{AUTHOR CONTRIBUTIONS}

C.H. and C.P. performed the FLIM imaging and analysis. C.H. and K.A.F. prepared fibroblast and SH-SY5Y samples. I.M. performed the AFM studies and analysis. D.F-A. prepared oesophagus tissue samples. C.L.N. and P.J.R-G. prepared ES cell samples and performed chromocenter analysis. M.S.H and K.C. prepared Rex1GFP ES cell samples. P.P.V wrote scripts for image analysis. C.H., C.P., K.A.F, C.F.K., and G.S.K.S. conceived and designed the experiments. C.H. and C.P. wrote the manuscript with help from C.N. and G.S.K.S.

\section{COMPETING FINANCIAL INTERESTS}

The authors declare no competing financial interests.

\section{Bibliography}

1. Job Dekker, Karsten Rippe, Martijn Dekker, and Nancy Kleckner. Capturing Chromosome Conformation. Science, 295(5558):1306-1311, feb 2002. doi: 10.1126/science.1067799.

2. E. Lieberman-Aiden, N. L. van Berkum, Louise Williams, Maxim Imakaev, Tobias Ragoczy, Agnes Telling, Ido Amit, Bryan R Lajoie, Peter J Sabo, Michael O Dorschner, Richard Sandstrom, Bradley Bernstein, M A Bender, Mark Groudine, Andreas Gnirke, John Stamatoyannopoulos, Leonid A Mirny, E. S. Lander, and J. Dekker. Comprehensive Mapping of Long-Range Interactions Reveals Folding Principles of the Human Genome. Science, 326 (5950):289-293, oct 2009. doi: 10.1126/science.1181369.

3. Matthew Denholtz, Giancarlo Bonora, Constantinos Chronis, Erik Splinter, Wouter De Laat, Jason Ernst, Matteo Pellegrini, and Kathrin Plath. Article Long-Range Chromatin Contacts in Embryonic Stem Cells Reveal a Role for Pluripotency Factors and Polycomb Proteins in Genome Organization. Stem Cell, 13(5):602-616, 2013. doi: 10.1016/j.stem.2013.08.013.

4. Josée Dostie, Todd A. Richmond, Ramy A. Arnaout, Rebecca R. Selzer, William L. Lee, Tracey A. Honan, Eric D. Rubio, Anton Krumm, Justin Lamb, Chad Nusbaum, Roland D. Green, and Job Dekker. Chromosome Conformation Capture Carbon Copy (5C): A massively parallel solution for mapping interactions between genomic elements. Genome Research, 16(10):1299-1309, 2006. doi: 10.1101/gr.5571506.

5. Mark J Solomon, Pamela L Larsen, and Alexander Varshavsky. Mapping protein-DNA interactions in vivo with formaldehyde: Evidence that histone $\mathrm{H} 4$ is retained on a highly transcribed gene. Cell, 53(6):937-947, 1988. doi: 10.1016/S0092-8674(88)90469-2.

6. Tarjei S Mikkelsen, Manching Ku, David B Jaffe, Biju Issac, Erez Lieberman, Georgia Giannoukos, Pablo Alvarez, William Brockman, Tae Kyung Kim, Richard P Koche, William Lee, Eric Mendenhall, Aisling O'Donovan, Aviva Presser, Carsten Russ, Xiaohui Xie, Alexander Meissner, Marius Wernig, Rudolf Jaenisch, Chad Nusbaum, Eric S Lander, and Bradley E Bernstein. Genome-wide maps of chromatin state in pluripotent and lineage-committed cells. Nature, 448(7153):553-560, 2007. doi: 10.1038/nature06008.

7. Jason D Buenrostro, Paul G Giresi, Lisa C Zaba, Howard Y Chang, and William J Greenleaf. Transposition of native chromatin for fast and sensitive epigenomic profiling of open chromatin, DNA-binding proteins and nucleosome position. Nature Methods, 10(12):12131218, 2013. doi: 10.1038/nmeth.2688.

8. Eran Meshorer, Dhananjay Yellajoshula, Eric George, Peter J Scambler, David T Brown, and Tom Misteli. Hyperdynamic plasticity of chromatin proteins in pluripotent embryonic stem cells. Developmental Cell, 10(1):105-116, 2006. doi: 10.1016/j.devcel.2005.10.017.

9. Sol Efroni, Radharani Duttagupta, Jill Cheng, Hesam Dehghani, Daniel J Hoeppner, Chandravanu Dash, David P. Bazett-Jones, Stuart Le Grice, Ronald D.G. McKay, Kenneth H Buetow, Thomas R Gingeras, Tom Misteli, and Eran Meshorer. Global Transcription in Pluripotent Embryonic Stem Cells. Cell Stem Cell, 2(5):437-447, 2008. doi: 10.1016/j.stem.2008.03.021

10. Bo Wen, Hao Wu, Yoichi Shinkai, Rafael A Irizarry, and Andrew P Feinberg. Large histone H3 lysine 9 dimethylated chromatin blocks distinguish differentiated from embryonic stem cells. Nature Genetics, 41(2):246-250, 2009. doi: 10.1109/JMEMS.2016.2614303.

11. Kashif Ahmed, Hesam Dehghani, Peter Rugg-Gunn, Eden Fussner, Janet Rossant, and David P. Bazett-Jones. Global chromatin architecture reflects pluripotency and lineage commitment in the early mouse embryo. PLOS ONE, 5(5), 2010. doi: 10.1371/journal. pone. 0010531 .

12. Cynthia L. Fisher and Amanda G Fisher. Chromatin states in pluripotent, differentiated, and reprogrammed cells. Current Opinion in Genetics and Development, 21(2):140-146, 2011. doi: 10.1016/j.gde.2011.01.015.

13. Patrick J Wijchers, Geert Geeven, Michael Eyres, Atze J Bergsma, Mark Janssen, Marjon Verstegen, Yun Zhu, Yori Schell, Carlo Vermeulen, Elzo De Wit, and Wouter De Laat. Characterization and dynamics of pericentromere-associated domains in mice. Genome Research, 25(7):958-969, 2015. doi: 10.1101/gr.186643.114.

14. Clara Lopes Novo, Biola Maria Javierre, Jonathan Cairns, Anne Segonds-Pichon, Steven W Wingett, Paula Freire-Pritchett, Mayra Furlan-Magaril, Stefan Schoenfelder, Peter Fraser, and Peter J. Rugg-Gunn. Long-Range Enhancer Interactions Are Prevalent in Mouse Embryonic Stem Cells and Are Reorganized upon Pluripotent State Transition. Cell Reports, 22(10):2601-2614, 2018. doi: 10.1016/j.celrep.2018.02.040.

15. Daan Peric-Hupkes, Wouter Meuleman, Ludo Pagie, Sophia W.M. Bruggeman, Irina Solovei, Wim Brugman, Stefan Gräf, Paul Flicek, Ron M. Kerkhoven, Maarten van Lohuizen, Marcel Reinders, Lodewyk Wessels, and Bas van Steensel. Molecular Maps of the Reorganization of Genome-Nuclear Lamina Interactions during Differentiation. Molecular Cell, 38 (4):603-613, 2010. doi: 10.1016/j.molcel.2010.03.016. 
bioRxiv preprint doi: https://doi.org/10.1101/2020.05.02.073536; this version posted May 2, 2020. The copyright holder for this preprint (which was not certified by peer review) is the author/funder, who has granted bioRxiv a license to display the preprint in perpetuity. It is made available under aCC-BY-ND 4.0 International license.

16. Hui Zheng and Wei Xie. The role of 3D genome organization in development and cell differentiation. Nature Reviews Molecular Cell Biology, 20(9):535-550, 2019. doi: 10.1038/ s41580-019-0132-4.

17. R. David Hawkins, Gary C. Hon, Leonard K. Lee, Queminh Ngo, Ryan Lister, Mattia Pelizzola, Lee E. Edsall, Samantha Kuan, Ying Luu, Sarit Klugman, Jessica AntosiewiczBourget, Zhen Ye, Celso Espinoza, Saurabh Agarwahl, Li Shen, Victor Ruotti, Wei Wang, Ron Stewart, James A. Thomson, Joseph R. Ecker, and Bing Ren. Distinct epigenomic landscapes of pluripotent and lineage-committed human cells. Cell Stem Cell, 6(5):479491, 2010. doi: 10.1016/j.stem.2010.03.018.

18. David Llères, John James, Sam Swift, David G. Norman, and Angus I. Lamond. Quantitative analysis of chromatin compaction in living cells using FLIM-FRET. Journal of Cell Biology, 187(4):481-496, 2009. doi: 10.1083/jcb.200907029.

19. Ashwat Visvanathan, Kashif Ahmed, Liron Even-Faitelson, David Lleres, David P. BazettJones, and Angus I. Lamond. Modulation of Higher Order Chromatin Conformation in Mammalian Cell Nuclei Can Be Mediated by Polyamines and Divalent Cations. PLOS ONE, 8(6), 2013. doi: 10.1371/journal.pone.0067689.

20. Jieqiong Lou, Lorenzo Scipioni, Belinda K. Wright, Tara K. Bartolec, Jessie Zhang, V. Pragathi Masamsetti, Katharina Gaus, Enrico Gratton, Anthony J. Cesare, and Elizabeth Hinde. Phasor histone FLIM-FRET microscopy quantifies spatiotemporal rearrangement of chromatin architecture during the DNA damage response. Proceedings of the National Academy of Sciences of the United States of America, 116(15):7323-7332, 2019. doi: 10.1073/pnas.1814965116.

21. Kevin J. Chalut, Markus Höpfler, Franziska Lautenschläger, Lars Boyde, Chii Jou Chan, Andrew Ekpenyong, Alfonso Martinez-Arias, and Jochen Guck. Chromatin decondensation and nuclear softening accompany Nanog downregulation in embryonic stem cells. Biophys ical Journal, 103(10):2060-2070, 2012. doi: 10.1016/j.bpj.2012.10.015.

22. Stephen Rea, Frank Eisenhaber, Dónal O'Carroll, Brian D Strahl, Zu-wen Sun, Manfred Schmid, Susanne Opravil, Karl Mechtler, Chris P Ponting, C David Allis, and Thomas Jenuwein. Regulation of chromatin structure by site-specific histone $\mathrm{H} 3$ methyltransferases. Nature, 406(6796):593-599, aug 2000. doi: 10.1038/35020506.

23. Justin S Becker, Dario Nicetto, and Kenneth S Zaret. H3K9me3-Dependent Heterochromatin : Barrier to Cell Fate Changes. Trends in Genetics, 32(1):29-41, 2016. doi: 10.1016/j.tig.2015.11.001.

24. Clara Lopes Novo, Calvin Tang, Kashif Ahmed, Ugljesa Djuric, Eden Fussner, Nicholas P. Mullin, Natasha P. Morgan, Jasvinder Hayre, Arnold R. Sienerth, Sarah Elderkin, Ryuich Nishinakamura, Ian Chambers, James Ellis, David P. Bazett-Jones, and Peter J. Rugg Gunn. The pluripotency factor Nanog regulates pericentromeric heterochromatin organization in mouse embryonic stem cells. Genes and Development, 30(9):1101-1115, 2016. doi: 10.1101/gad.275685.115.

25. David P. Bazett-Jones. Electron spectroscopic imaging of chromatic and other nucleoprotein complexes. Methods, 5(1):37-58, 1992. doi: 10.1016/0892-0354(92)90004-A.

26. David P. Bazett-Jones, Ren Li, Eden Fussner, Rosa Nisman, and Hesam Dehghani. Elucidating chromatin and nuclear domain architecture with electron spectroscopic imaging Chromosome Research, 16(3):397-412, 2008. doi: 10.1007/s10577-008-1237-3.

27. Horng D. Ou, Sébastien Phan, Thomas J. Deerinck, Andrea Thor, Mark H. Ellisman, and Clodagh C. O'Shea. ChromEMT: Visualizing 3D chromatin structure and compaction in interphase and mitotic cells. Science, 357(6349), 2017. doi: 10.1126/science.aag0025.

28. Marianne Frommer, L. E. McDonald, Douglas S Millar, C. M. Collis, F. Watt, G. W. Grigg, P. L. Molloy, and Cheryl L Paul. A genomic sequencing protocol that yields a positive display of 5-methylcytosine residues in individual DNA strands. Proceedings of the National Academy of Sciences, 89(5):1827-1831, 1992. doi: 10.1073/pnas.89.5.1827.

29. Ehsan Habibi, Arie B Brinkman, Julia Arand, Leonie I Kroeze, Hindrik H.D. Kerstens, Filomena Matarese, Konstantin Lepikhov, Marta Gut, Isabelle Brun-Heath, Nina C Hubner, Rosaria Benedetti, Lucia Altucci, Joop H Jansen, Jörn Walter, Ivo G Gut, Hendrik Marks and Hendrik G Stunnenberg. Whole-genome bisulfite sequencing of two distinct interconvertible DNA methylomes of mouse embryonic stem cells. Cell Stem Cell, 13(3):360-369, 2013. doi: 10.1016/j.stem.2013.06.002.

30. Kristina Haase, Andrew E Pelling, and Kristina Haase. Investigating cell mechanics with atomic force microscopy Author for correspondence : (March 2015), 2016. doi: 10.1098/rsif.

31. Jan Lammerding. Mechanics of the nucleus. Comprehensive Physiology, 1(2):783-807, 2011. doi: $10.1002 /$ cphy.c100038.

32. Stefano Pagliara, Kristian Franze, Crystal R. McClain, George W. Wylde, Cynthia L. Fisher, Robin J M Franklin, Alexandre J Kabla, Ulrich F Keyser, and Kevin J. Chalut. Auxetic nucle in embryonic stem cells exiting pluripotency. Nature Materials, 13(6):638-644, jun 2014. doi: $10.1038 /$ nmat3943.

33. Farshid Guilak, John R. Tedrow, and Rainer Burgkart. Viscoelastic properties of the cell nucleus. Biochemical and Biophysical Research Communications, 269(3):781-786, 2000. doi: $10.1006 /$ bbrc. 2000.2360

34. Jan Lammerding, Loren G Fong, Julie Y Ji, Karen Reue, Colin L Stewart, Stephen G Young, and Richard T Lee. Lamins A and C but Not Lamin B1 Regulate Nuclear Mechanics. Journal of Biological Chemistry, 281(35):25768-25780, 2006. doi: 10.1074/jbc.M513511200.

35. Andrew D Stephens, Edward J Banigan, Stephen A Adam, Robert D Goldman, and John F. Marko. Chromatin and lamin A determine two different mechanical response regimes of the cell nucleus. Molecular Biology of the Cell, 28(14):1984-1996, 2017. doi: 10.1091/mbc. E16-09-0653.

36. Stephen T. Spagnol and Kris Noel Dahl. Spatially resolved quantification of chromatin condensation through differential local rheology in cell nuclei fluorescence lifetime imaging PLOS ONE, 11(1):1-19, 2016. doi: 10.1371/journal.pone.0146244.

37. Ana Katrina Estandarte, Stanley Botchway, Christophe Lynch, Mohammed Yusuf, and Ian Robinson. The use of DAPI fluorescence lifetime imaging for investigating chromatin condensation in human chromosomes. Scientific Reports, 6(1):31417, 2016. doi: 10.1038/srep31417.

38. David Llères, Aymeric P. Bailly, Aurélien Perrin, David G. Norman, Dimitris P. Xirodimas, and Robert Feil. Quantitative FLIM-FRET Microscopy to Monitor Nanoscale Chromatin Compaction In Vivo Reveals Structural Roles of Condensin Complexes. Cell Reports, 18 (7):1791-1803, 2017. doi: 10.1016/j.celrep.2017.01.043
39. Gražvydas Lukinavičius, Claudia Blaukopf, Elias Pershagen, Alberto Schena, Luc Reymond, Emmanuel Derivery, Marcos Gonzalez-Gaitan, Elisa D'Este, Stefan W. Hell, Danie Wolfram Gerlich, and Kai Johnsson. SiR-Hoechst is a far-red DNA stain for live-cell nanoscopy. Nature Communications, 6:8497, 2015. doi: 10.1038/ncomms9497.

40. Joseph R. Lakowicz. Principles of fluorescence spectroscopy. Springer, 2006. ISBN 9780387463124

41. Marina K. Kuimova, Gokhan Yahioglu, James A. Levitt, and Klaus Suhling. Molecular roto measures viscosity of live cells via fluorescence lifetime imaging. Journal of the American Chemical Society, 130(21):6672-6673, 2008. doi: 10.1021/ja800570d.

42. Weiyue Chen, Laurence J. Young, Meng Lu, Alessio Zaccone, Florian Strohl, Na Yu, Gabriele S.Kaminski Schierle, and Clemens F. Kaminski. Fluorescence self-quenching from reporter dyes informs on the structural properties of amyloid clusters formed in vitro and in cells. Nano Letters, 17(1):143-149, 2017. doi: 10.1021/acs.nanolett.6b03686.

43. Adai Colom, Emmanuel Derivery, Saeideh Soleimanpour, Caterina Tomba, Marta Da Molin, Naomi Sakai, Marcos González-Gaitán, Stefan Matile, and Aurélien Roux. A fluorescent membrane tension probe. Nature Chemistry, 10(11):1118-1125, 2018. doi: 10.1038/s41557-018-0127-3

44. Klaus Suhling, Liisa M. Hirvonen, James a. Levitt, Pei-Hua Chung, Carolyn Tregidgo, Alix Le Marois, Dmitri a. Rusakov, Kaiyu Zheng, Simon Ameer-Beg, Simon Poland, Simao Coelho, Robert Henderson, and Nikola Krstajic. Fluorescence lifetime imaging (FLIM): Basic concepts and some recent developments. Medical Photonics, 44:3-40, 2015. doi: 10.1016/j.medpho.2014.12.001.

45. Wolfgang Becker. Fluorescence lifetime imaging - techniques and applications. Journal of Microscopy, 247(2):119-136, 2012. doi: 10.1111/j.1365-2818.2012.03618.x.

46. Enrico Gratton, Sophie Breusegem, Jason Sutin, Qiaoqiao Ruan, and Nicholas Barry. Fluorescence lifetime imaging for the two-photon microscope: time-domain and frequencydomain methods. Journal of Biomedical Optics, 8(3):381, 2003. doi: 10.1117/1.1586704.

47. Sharon Schlesinger and Eran Meshorer. Open Chromatin, Epigenetic Plasticity, and Nuclear Organization in Pluripotency. Developmental Cell, 48(2):135-150, 2019. doi: 10.1016/j.devcel.2019.01.003

48. Eden Fussner, Ugljesa Djuric, Mike Strauss, Akitsu Hotta, Carolina Perez-iratxeta, Fredrik Lanner, F Jeffrey Dilworth, James Ellis, and David P Bazett-jones. Constitutive heterochromatin reorganization during somatic cell reprogramming. The EMBO Journal, 30(9):17781789, 2011. doi: 10.1038/emboj.2011.96.

49. Elzo De Wit, Britta A.M. Bouwman, Yun Zhu, Petra Klous, Erik Splinter, Marjon J.A.M. Verstegen, Peter H.L. Krijger, Nicola Festuccia, Elphège P. Nora, Maaike Welling, Edith Heard, Niels Geijsen, Raymond A Poot, lan Chambers, and Wouter De Laat. The pluripotent genome in three dimensions is shaped around pluripotency factors. Nature, 501(7466): 227-231, 2013. doi: 10.1038/nature12420.

50. Anand Pillarisetti, Jaydev P Desai, Hamid Ladjal, Andrew Schiffmacher, Antoine Ferreira, and Carol L Keefer. Mechanical Phenotyping of Mouse Embryonic Stem Cells: Increase in Stiffness with Differentiation. Cellular Reprogramming (Formerly "Cloning and Stem Cells"), 13(4):371-380, 2011. doi: 10.1089/cell.2011.0028.

51. J David Pajerowski, Kris Noel Dahl, Franklin L Zhong, Paul J Sammak, and Dennis E Discher. Physical plasticity of the nucleus in stem cell differentiation. Proceedings of the $\mathrm{Na}$ tional Academy of Sciences, 104:15619-15624, 2007. doi: 10.1073/pnas.0702576104.

52. Jose Silva, Ornella Barrandon, Jennifer Nichols, Jitsutaro Kawaguchi, Thorold W Theunissen, and Austin Smith. Promotion of reprogramming to ground state pluripotency by signal inhibition. PLoS Biology, 6(10):2237-2247, 2008. doi: 10.1371/journal.pbio.0060253.

53. Carla Mulas, Tüzer Kalkan, Ferdinand von Meyenn, Harry G. Leitch, Jennifer Nichols, and Austin Smith. Defined conditions for propagation and manipulation of mouse embryonic stem cells. Development, 146(6):dev173146, mar 2019. doi: 10.1242/dev.173146.

54. Hendrik Marks, Tüzer Kalkan, Roberta Menafra, Sergey Denissov, Kenneth Jones, Helmut Hofemeister, Jennifer Nichols, Andrea Kranz, A. Francis Stewart, Austin Smith, and Hendrik G Stunnenberg. The transcriptional and epigenomic foundations of ground state pluripotency. Cell, 149(3):590-604, 2012. doi: 10.1016/j.cell.2012.03.026.

55. Harry G Leitch, Kirsten R Mcewen, Aleksandra Turp, Vesela Encheva, Tom Carroll, Nils Grabole, William Mansfield, Buhe Nashun, Jaysen G Knezovich, Austin Smith, M Azim Surani, and Petra Hajkova. Articles Naive pluripotency is associated with global DNA hypomethylation. Nature Publishing Group, 20(3):311-316, 2013. doi: 10.1038/nsmb.2510.

56. Austin Smith. Design principles of pluripotency. EMBO Molecular Medicine, 1(5):251-254, 2009. doi: 10.1002/emmm.200900035.

57. Austin Smith. Formative pluripotency: The executive phase in a developmental continuum. Development, 144(3):365-373, 2017. doi: 10.1242/dev.142679.

58. Tüzer Kalkan, Nelly Olova, Mila Roode, Carla Mulas, Heather J. Lee, Isabelle Nett, Hendrik Marks, Rachael Walker, Hendrik G. Stunnenberg, Kathryn S. Lilley, Jennifer Nichols, Wolf Reik, Paul Bertone, and Austin Smith. Tracking the embryonic stem cell transition from ground state pluripotency. Development, 144(7):1221-1234, 2017. doi: 10.1242/dev.142711.

59. Michal R. Gdula, Krzysztof Poterlowicz, Andrei N. Mardaryev, Andrey A. Sharov, Yonghong Peng, Michael Y. Fessing, and Vladimir A. Botchkarev. Remodeling of three-dimensional organization of the nucleus during terminal keratinocyte differentiation in the epidermis Journal of Investigative Dermatology, 133(9):2191-2201, 2013. doi: 10.1038/jid.2013.66.

60. Marius Walter, Aurélie Teissandier, Raquel Pérez-Palacios, and Déborah Bourc'his. An epigenetic switch ensures transposon repression upon dynamic loss of DNA methylation in embryonic stem cells. eLife, 5(1):n/a-n/a, jan 2016. doi: 10.7554/eLife.11418.

61. Matteo Tosolini, Vincent Brochard, Pierre Adenot, Martine Chebrout, Giacomo Grillo, Violette Navia, Nathalie Beaujean, Claire Francastel, Amélie Bonnet-Garnier, and Alice Jouneau. Contrasting epigenetic states of heterochromatin in the different types of mouse pluripotent stem cells. Scientific Reports, 8(1):1-14, 2018. doi: 10.1038/ s41598-018-23822-4.

62. Onkar Joshi, Shuang Yin Wang, Tatyana Kuznetsova, Yaser Atlasi, Tianran Peng, Pierre J. Fabre, Ehsan Habibi, Jani Shaik, Sadia Saeed, Lusy Handoko, Todd Richmond, Mikhai Spivakov, Daniel Burgess, and Hendrik G. Stunnenberg. Dynamic Reorganization of Ex tremely Long-Range Promoter-Promoter Interactions between Two States of Pluripotency. Cell Stem Cell, 17(6):748-757, 2015. doi: 10.1016/j.stem.2015.11.010. 
bioRxiv preprint doi: https://doi.org/10.1101/2020.05.02.073536; this version posted May 2, 2020. The copyright holder for this preprint (which was not certified by peer review) is the author/funder, who has granted bioRxiv a license to display the preprint in perpetuity. It is made Illuminating chromatin compaction in live cells and fixed tissues using SiR-DNA fluorescence lifetime

\section{Supplementary Note 1: Materials and Methods}

\section{Cell culture}

Human HFF-1 fibroblasts from the American Type Culture Collection were cultured in Dulbecco's Modified Eagle's Medium (Gibco, Thermo Fisher Scientific, Waltham, MA, USA) with 10\% fetal bovine serum (FBS, Gibco), 1\% GlutaMAX (Gibco), and 1\% antibiotic-antimycotic (Gibco). Human SH-SY5Y neuroblastoma cells from the European Collection of Cell Cultures were cultured in 41\% Minimum Essential Medium (Gibco), 41\% Ham's F-12 Nutrient Mixture (Gibco), 15\% FBS, $1 \%$ nonessential medium (Gibco), $1 \%$ GlutaMAX (Gibco), $1 \%$ antibiotic-antimycotic (Gibco).

Mouse E14Tg2a (also referred to as E14) is a male mESC line of 129/Ola background (1). E14Tg2a, E14Tg2a-derived Nanog $^{-1-}(\mathrm{RCN} \beta \mathrm{H}-\mathrm{B}(\mathrm{t}))(2)$, were cultured on gelatine-coated plastic in standard ESC medium (DMEM with $15 \% \mathrm{FBS}, 1 \mathrm{mM}$ sodium pyruvate, $0.1 \mathrm{mM}$ 2-mercaptoethanol, $0.1 \mathrm{mM}$ nonessential amino acids, $1 \%$ GlutaMAX, $1000 \mathrm{U} / \mathrm{mL}$ LIF). For naïve reprogramming, E14 cells and Rex1GFPd2 reporter mESCs were cultured on gelatine-coated plastic (coated with $0.1 \%$ gelatine in PBS, RT for 30 minutes) in serum-free N2B27 supplemented with 2i inhibitors, 1uM PD0325901 (MEK inhibitor) $+3 \mu \mathrm{M}$ Chiron (CHIR99021, GSK3 inhibitor) + 100U/ml LIF. N2B27 was made with equal parts of Neurobasal media (Gibco) and Invitrogen DMEM F-12 (Gibco), supplemented with $0.1 \mathrm{mM}$ 2-mercaptoethanol (ThermoFisher), 0.5\% N2 (made in-house (3)), 1\% B27 (ThermoFisher), 2mM L-glutamine (ThermoFisher), 0.1\% BSA (ThermoFisher) and $12.5 \mu \mathrm{g} / \mathrm{ml}$ human recombinant insulin zinc (ThermoFisher). mESCs cultured in $2 \mathrm{i}$ were split with Accutase (Millipore) every 2-3 days and seeded at $1.5 \times 10^{4}$ cells $/ \mathrm{cm}^{2}$. Exit from naïve pluripotency was initiated by re-plating cells in N2B27 without $2 \mathrm{i}$ inhibitors at a density of $1 \times 10^{4}$ cells $/ \mathrm{cm}^{2}$ on laminin coated dishes (coated overnight incubation at $10 \mu \mathrm{g} / \mathrm{ml}$ at $4^{\circ} \mathrm{C}$ ) at $3,9,17,25,34$, and 48 hours before imaging.

\section{SiR-DNA staining}

For SiR-DNA-based analysis of chromatin compaction by FLIM, cells were plated in $35 \mathrm{~mm}$ glass bottom dishes (P35-1.514-C, Mattek Corporation, MA, USA) the day before the start of the experiment. Cells were stained with $1 \mu$ M SiR-DNA (Spirochrome Ltd., Stein am Rhein, Switzerland) with $10 \mu \mathrm{M}$ verapamil (Spirochrome Ltd.) in cell culture medium for 1 hour, before changing to cell culture medium containing $10 \mu \mathrm{M}$ verapamil and $20 \mathrm{mM}$ HEPES pH 7.4 for imaging. Nuclear compaction or decompaction treatments $(10 \mathrm{mM}$ sodium azide and $50 \mathrm{mM}$ 2-deoxyglucose; $200 \mathrm{ng} / \mathrm{ml}$ Trichostatin A; or 20\% dextrose) were included in the staining and imaging medium.

\section{Mouse Oesophagus}

Optimal cutting temperature compound (OCT) embedded C57BL/6J oesophageal cryosections of $10 \mu \mathrm{m}$ thickness were fixed with $2 \%$ paraformaldehyde for 5 min. After two washes in PBS, slides were incubated in blocking buffer (0.5\% bovine serum albumin, $0.25 \%$ fish skin gelatine, $0.5 \%$ Triton X-100 and 10\% donkey serum, in PBS) and stained in the same buffer with SiR-DNA and Alexa Fluor 488 Wheat Germ Agglutinin for 5 minutes at room temperature. Samples were washed twice in PBS and mounted using 50/50 PBS glycerol.

\section{Fluorescence lifetime imaging (FLIM)}

All samples were assayed on a home-built confocal platform (Olympus Fluoview FV300) integrated with time-correlated single photon counting (TCSPC) to measure fluorescence lifetime in every image pixel. To excite SiR-DNA, output from a pulsed supercontinuum source (WL-SC-400-15, Fianium Ltd., UK, repetition rate 40MHz) was filtered using an acousto-optic tunable filter (AA Optoelectronic AOTFnC-VIS) to obtain a narrow wavelength band centered at 640nm and an additional bandpass filter FF01-635/18 was used to cleanup excitation light. Fluorescence emission from the sample was filtered using 700/70nm (Comar Optics, U.K.) before passing onto a photomultiplier tube (PMC-100, Becker\&Hickl GmbH, Berlin, Germany). Photons were recorded in time-tagged, time-resolved mode that permits sorting photons from each pixel into a histogram according to their arrival times. The data was recorded by a TCSPC module (SPC-830, Becker\&Hickl GmBH). Photons were acquired for 200 seconds to make a single $256 \times 256$ FLIM image. Photon count rates were always kept below $1 \%$ of the laser repetition rate to prevent pulse pile-up. Photobleaching was verified to be negligible during acquisition. Approximately 10 representative images with several nuclei per field of view were acquired for each condition.

\section{FLIM Analysis}

All FLIM images were analysed using FLIMfit v4.12.1(4) and fitted with a monoexponential decay function (S1). For the analysis of fibroblasts and SH-SY5Y cells, an average fluorescence lifetime per nucleus was obtained from a large field of view using intensity-based segmentation. For images displayed in figures, lifetimes were fitted per pixel. For the analysis of stem cell nuclei images in 2, whole nuclei were segmented based on intensity (debris and mitotic nuclei were manually removed). A two-level mask separating heterochromatin spots and euchromatin (S5) was created with Icy software spot detection tool $(5,6)$. Pixels in these two chromatin regions were binned and fitted separately to obtain two lifetime values for each image (demonstrated in Fig 2). For the analysis of Rex1-GFP stem cell nuclei, the masks were separated into single cells using a custom Matlab (MathWorks, MA, USA) script, to obtain the lifetime of the euchromatin and heterochromatin in each cell. 
bioRxiv preprint doi: https://doi.org/10.1101/2020.05.02.073536; this version posted May 2, 2020. The copyright holder for this preprint (which

was not certified by peer review) is the author/funder, who has granted bioRxiv a license to display the preprint in perpetuity. It is made

Illuminating chromatin compaction in live cells and fixed tissues using SiR-DNA fluorescence lifetime

These masks were also used to measure the corresponding GFP intensity of each cell, and the lifetime and GFP intensity data were combined (Fig S4) using R (7, 8). Data were plotted with Origin 2018b (OriginLab, Northampton, MA) and statistical analysis was carried out using Graphpad Prism 7 (La Jolla, California, USA).

\section{Atomic Force Microscopy}

For AFM nuclear stiffness measurements, cells were plated at 2x10 5 cells per $50 \mathrm{~mm}$ glass bottom dish (GWST-5040, Willco Wells BV, Amsterdam, The Netherlands) the day before imaging. Cells were treated with nuclear compaction or decompaction treatments (see above) in cell culture medium for 1 hour, before changing to Dynamic Imaging Medium (150 mM NaCl, $5 \mathrm{mM}$ $\mathrm{KCl}, 1 \mathrm{mM} \mathrm{MgCl}, 1 \mathrm{mM} \mathrm{CaCl}$, $5 \mathrm{mM}$ glucose, $10 \mathrm{mM}$ HEPES pH 7.4) containing the chemical treatments during AFM imaging.

Atomic force microscopy measurements were performed on a Bioscope Resolve bioAFM (Bruker, Billerica, MA, USA), operated in PeakForce QNM mode. Live Cell probes (PFQNM-LC, Bruker AFM probes) were used for all experiments. The probes were pre-calibrated for spring constant (nominal $0.08 \mathrm{~N} / \mathrm{m}$ ) and its deflection sensitivity was measured at the start of the experiment, using a no-touch calibration. The sample stage was heated and maintained at $37^{\circ} \mathrm{C}$. The force applied to the cells was kept constant throughout the experiments and was less than $1 \mathrm{nN}$, with typical values being $400-600 \mathrm{pN}$.

\section{Analysis of Chromocenter Morphology}

DAPI linescan analyses were performed using ImageJ on optical sections where DAPI foci were at optimal focal planes. Fluorescence intensity histograms were generated through the nucleus and the background (outside the nucleus) was subtracted from the nucleoplasmic (baseline fluorescence within nucleus) and chromocentre signals. Variations in these data were calculated as a ratio of chromocentre peak height to nucleoplasmic signal.

\section{Bibliography}

1. M Hooper, K Hardy, A Handyside, S Hunter, and M Monk. HPRT-deficient (Lesch-Nyhan) mouse embryos derived from germline colonization by cultured cells. Nature, 326:292-295, 1987. doi: $10.1038 / 326292 \mathrm{a} 0$.

2. Ian Chambers, Jose Silva, Douglas Colby, Jennifer Nichols, Bianca Nijmeijer, Morag Robertson, Jan Vrana, Ken Jones, Lars Grotewold, and Austin Smith. Nanog safeguards pluripotency and mediates germline development. Nature, 450(7173):1230-1234, 2007. doi: 10.1038/nature06403.

3. Carla Mulas, Tüzer Kalkan, Ferdinand von Meyenn, Harry G. Leitch, Jennifer Nichols, and Austin Smith. Defined conditions for propagation and manipulation of mouse embryonic stem cells. Development, 146(6):dev173146, mar 2019. doi: 10.1242/dev.173146.

4. Sean C. Warren, Anca Margineanu, Dominic Alibhai, Douglas J. Kelly, Clifford Talbot, Yuriy Alexandrov, lan Munro, Matilda Katan, Chris Dunsby, and Paul M W French. Rapid Global Fitting of Large Fluorescence Lifetime Imaging Microscopy Datasets. PLOS ONE, 8(8), 2013. doi: 10.1371/journal.pone.0070687.

5. Fabrice De Chaumont, Stéphane Dallongeville, Nicolas Chenouard, Nicolas Hervé, Sorin Pop, Thomas Provoost, Vannary Meas-Yedid, Praveen Pankajakshan, Timothée Lecomte, Yoann Le Montagner, Thibault Lagache, Alexandre Dufour, and Jean Christophe Olivo-Marin. Icy: An open bioimage informatics platform for extended reproducible research. Nature Methods, 9(7):690-696, 2012. doi: 10.1038/nmeth.2075.

6. Jean Christophe Olivo-Marin. Extraction of spots in biological images using multiscale products. Pattern Recognition, 35(9):1989-1996, 2002. doi: 10.1016/S0031-3203(01)00127-3

7. R Core Team. R: A Language and Environment for Statistical Computing, 2017.

8. Hadley Wickham. ggplot2: Elegant Graphics for Data Analysis. Springer-Verlag New York, 2009. ISBN 978-0-387-98140-6. 
bioRxiv preprint doi: https://doi.org/10.1101/2020.05.02.073536; this version posted May 2, 2020. The copyright holder for this preprint (which was not certified by peer review) is the author/funder, who has granted bioRxiv a license to display the preprint in perpetuity. It is made Illuminating chromatin compaction in live cells and fixed tissues using SiR-DNA fluorescence lifetime

a

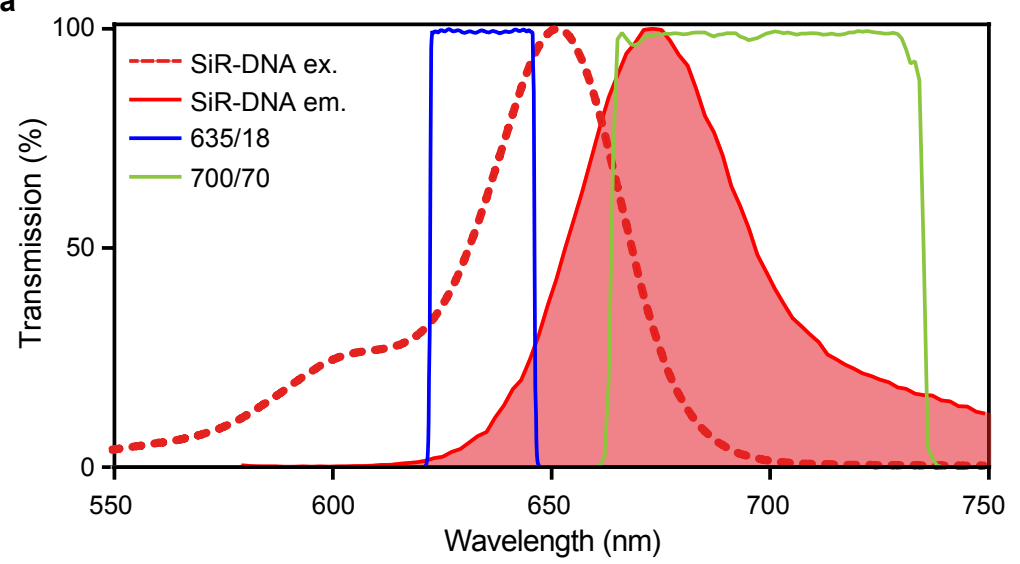

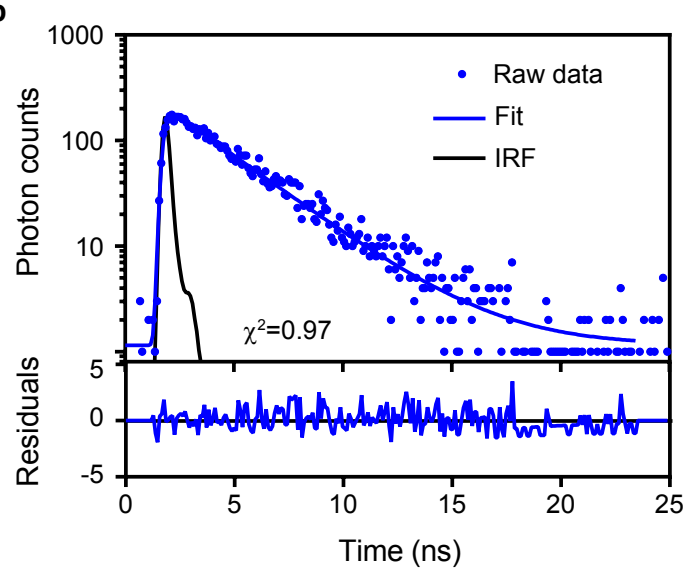

Fig. S1. Fluorescence properties of SiR-DNA. (A) Excitation and emission spectra from the Spirochrome Ltd., with excitation and emission filters used in this study. (B) Typical fluorescence decay curve of SiR-DNA from a $3 \times 3$ pixel bin, with a monoexponential decay fitted using FLIMfit and fit residuals (error) plotted. The fluorescence decay curve is from a representative TCSPC-FLIM image of fibroblasts stained with SiR-DNA. IRF: Instrument Response Function

a

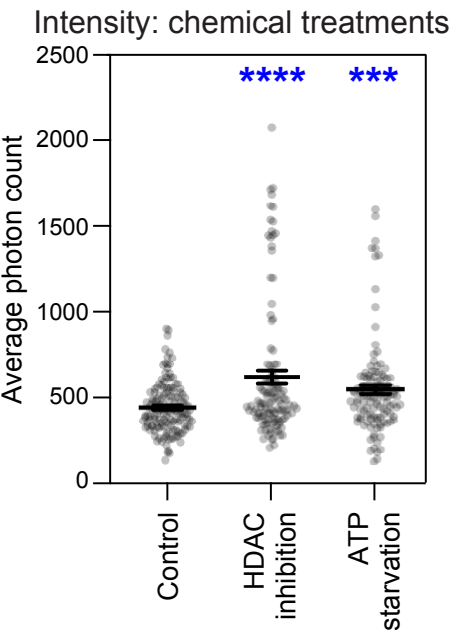

b

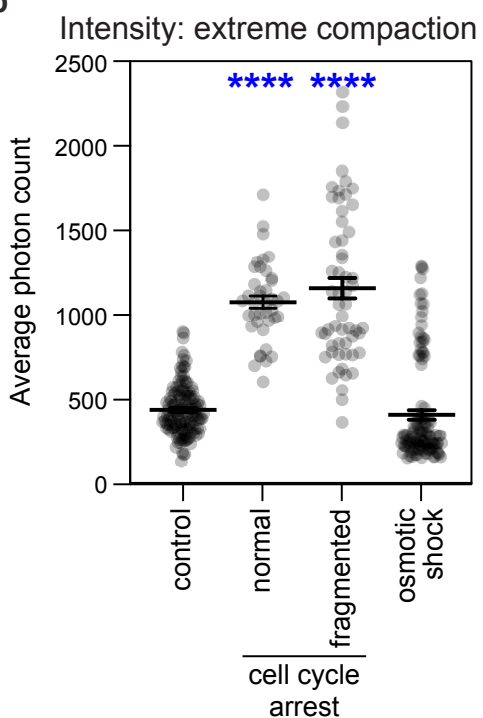

Fig. S2. SiR-DNA fluorescence intensity does not correlate with chromatin compaction. (a) Fluorescence intensity from fibroblast images used in Fig 1a and (b) Fluorescence intensity from fibroblast images used in Fig 1e show that different samples have different fluorescence intensities, but these do not correlate with chromatin compaction or decompaction. All treatments compared to control, unpaired one-way ANOVA with Sidak's multiple comparisons test. Mean $+/$ - SEM is shown for each plot. ${ }^{* * *} p<0.001,{ }^{* * * *} p<0.0001$. 
bioRxiv preprint doi: https://doi.org/10.1101/2020.05.02.073536; this version posted May 2, 2020. The copyright holder for this preprint (which was not certified by peer review) is the author/funder, who has granted bioRxiv a license to display the preprint in perpetuity. It is made Illuminating chromatin compaction in live cells and fixed tissues using SiR-DNA fluorescence lifetime

a

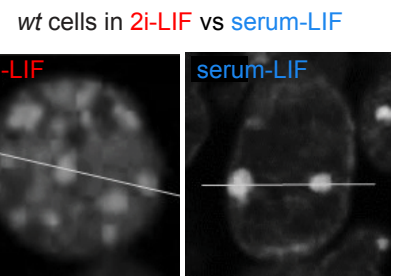

Confocal linescan profiles

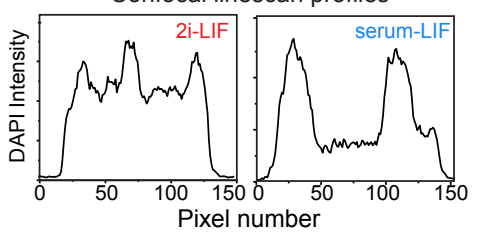

b

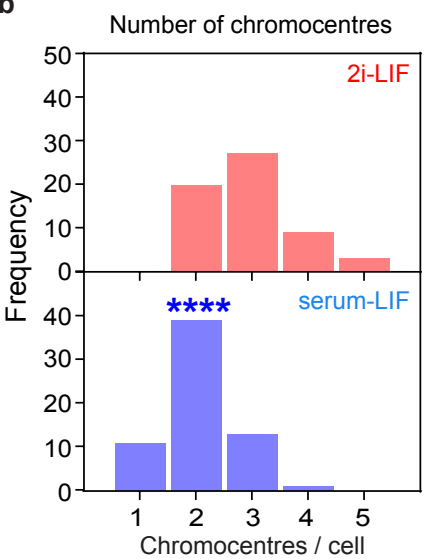

c

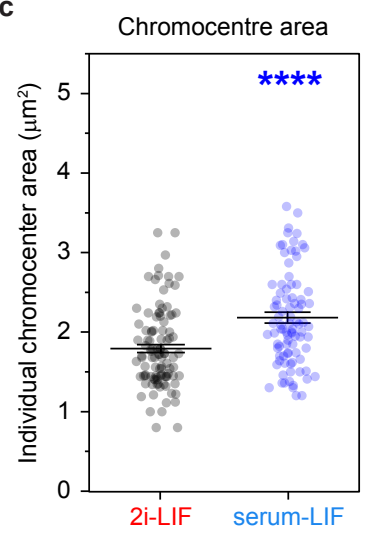

d

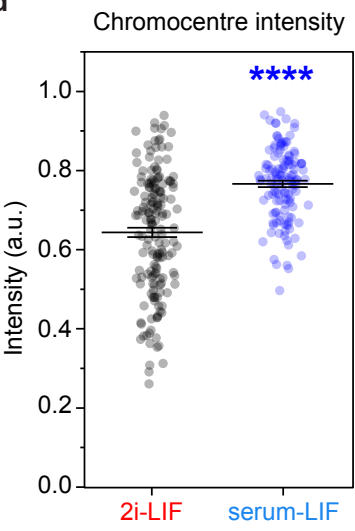

Fig. S3. Chromocentre morphology analysis of DAPI-stained ES cells shows that naïve cells (2i-LIF medium) had decreased chromocentre intensity and total chromocentre area compared to transition cells (serum-LIF medium). (a) Linescan profile and (b) chromocenter counting of DAPI stained ES cells show that naïve ES cell nuclei (2i-LIF medium) had increased numbers of chromocenters but (c) reduced area of individual chromocentres. (d) Chromocentre intensity analysis shows that naïve ES cells (2i-LIF medium) also had reduced chromocentre intensity. 3 independent experiments with $>40$ cells were analysed per sample. Mean $+/-$ SEM is shown for each plot. Data in b, $\mathrm{c}$ and $\mathrm{d}$ were analysed using unpaired two-tailed t-test with Welch's correction. ${ }^{* * * *} \mathrm{p}<0.0001$.

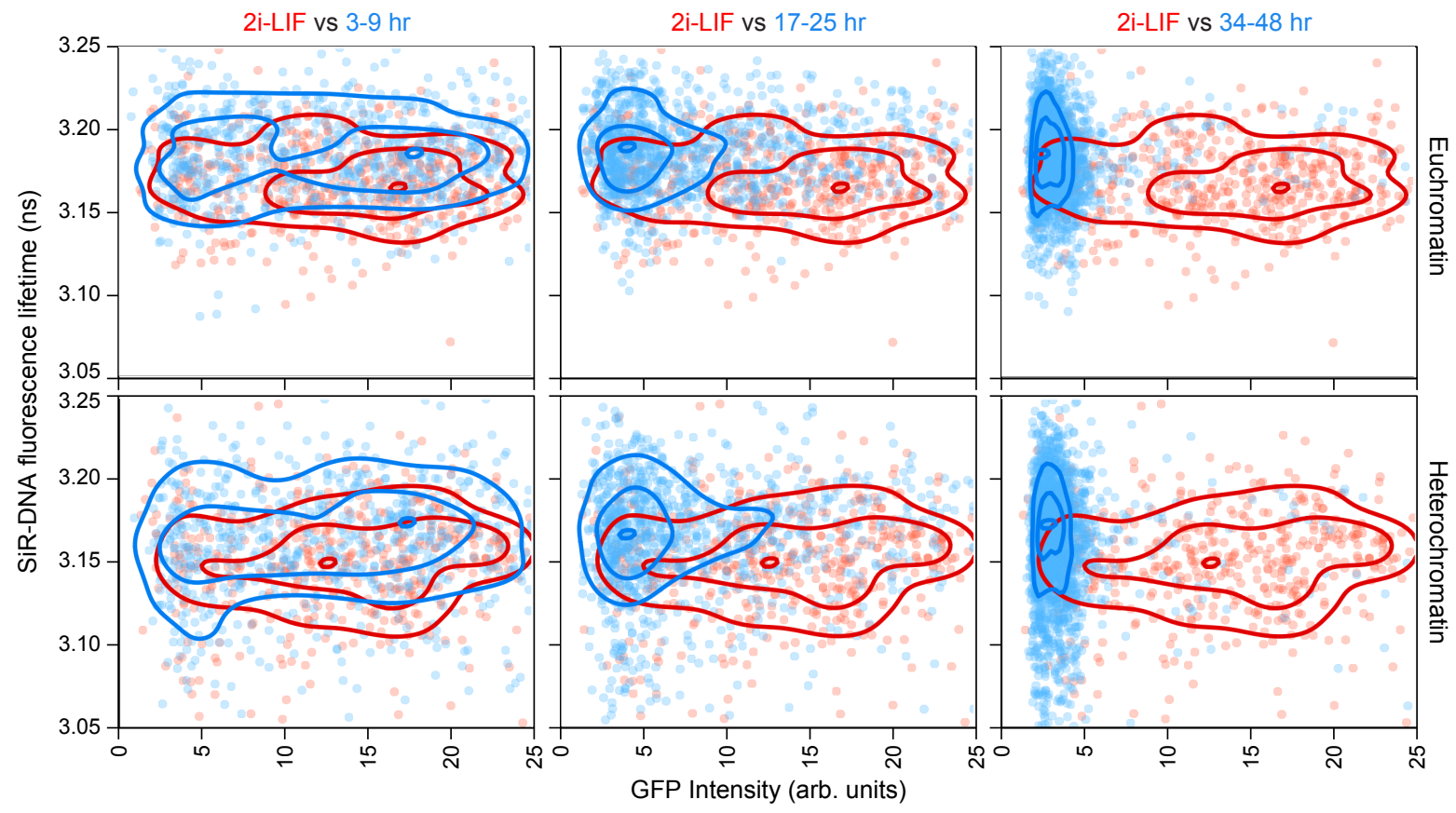

Fig. S4. Timecourse of $2 \mathrm{i}$ withdrawal in Rex1-GFP ES cells shows that naïve embryonic stem cells have undergone genome decompaction in both euchromatin and heterochromatin. Single-cell analysis of GFP intensity (Rex1-GFP level) and SiR-DNA fluorescence lifetime (chromatin compaction) shows that cells lost Rex1 expression and increased SiR-DNA fluorescence lifetime (decompacted), as they transitioned out of the naïve cell state. Each point represents one cell, 3 independent experiments with $>9$ images per sample. 
bioRxiv preprint doi: https://doi.org/10.1101/2020.05.02.073536; this version posted May 2, 2020. The copyright holder for this preprint (which was not certified by peer review) is the author/funder, who has granted bioRxiv a license to display the preprint in perpetuity. It is made Illuminating chromatin compaction in live cells and fixed tissues using SiR-DNA fluorescence lifetime

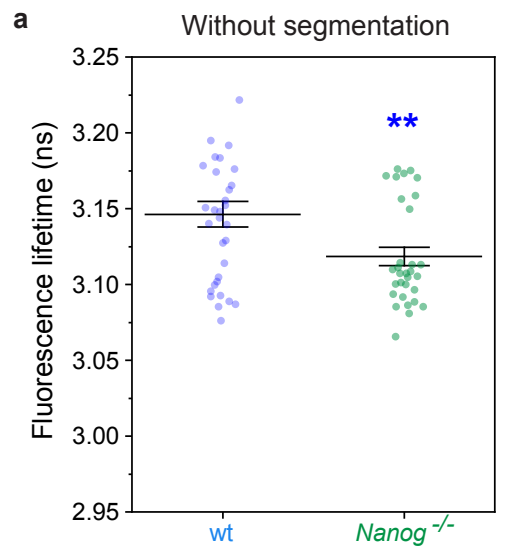

b

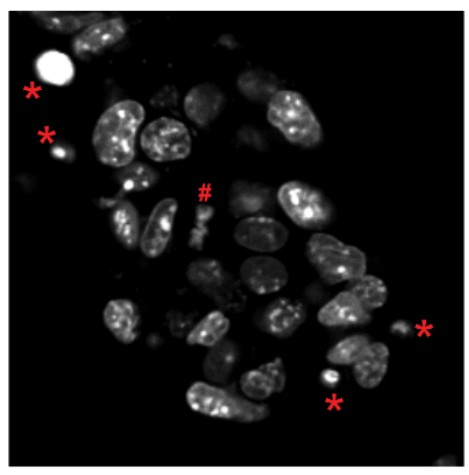

C

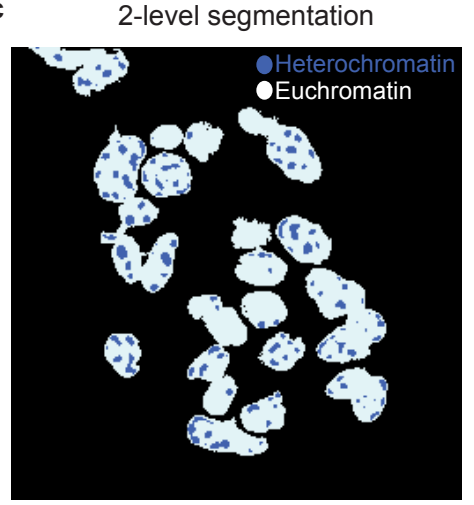

Fig. S5. Spot detection strategy to segment euchromatin from heterochromatin. (a) Plot of SiR-DNA fluorescence lifetimes show that Nanog-/- ES cell nuclei have a lower fluorescence lifetime (are more compact) than wildtype ES cell nuclei, even without segmentation of nuclei into heterochromatin and euchromatin. These plots are based on the same data as in Figure $2 \mathrm{~d}$ and e. Mean $+/-$ SEM is shown in the plot. Unpaired t-test with Welch's correction, ${ }^{\star *} p<0.01$. (b) Representative intensity image. A threshold was used to segment the nuclei, and then debris $\left(^{*}\right)$ and mitotic nuclei $(\#)$ were manually removed from the mask. The Spot Detector algorithm using the image analysis software lcy was used to segment the heterochromatin spots. The nuclei mask and the heterochromatin mask were multiplied together to remove spots detected outside the curated nuclei, and the resulting curated heterochromatin mask was added to the nuclei mask to make a two-level mask for import into the FLIMfit Segmentation Manager. (c) Image of the resulting two-level mask, with euchromatin in white and heterochromatin in blue. 